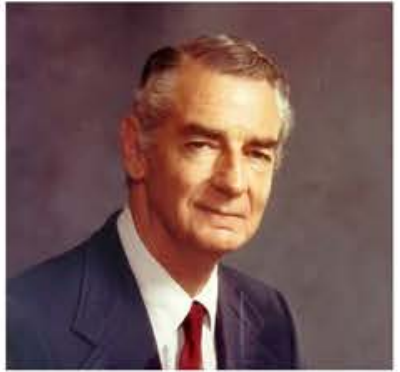

\section{Philip Palmer}

Philip Palmer died on 3 January 2013 at the age of 91 years. He had led an amazingly productive life, and leaves a lasting legacy in his contributions to radiology in developing countries.

Born into a medical family in 1921, Philip saw service as a stretcher bearer in World War II. After graduating in medicine at the London University in 1944, he was in general practice for a while and then specialised in radiology. In 1954 he emigrated with his family to Bulawayo in Southern Rhodesia (now Zimbabwe). At that time Mpilo Hospital, where he was stationed, had an outstanding group of medical staff, many of whom were later appointed professors in various parts of the world. Philip contributed in no small measure to this concetration of expertise, and enhanced and expanded radiological services (therapeutic and diagnostic) in the region. Even at this stage of his career he was appointed to international radiology committees.

From 1964 to 1968 Philip was professor and head of the Department of Radiology at the University of Cape Town. During this short period he totally reorganised radiological services and training, which had a lasting impact on UCT and the country. He oversaw the massive re-equipping of radiology departments in the UCT teaching hospitals and attracted many young and talented trainee and qualified radiologists. His clinical teaching sessions significantly advanced the radiology discipline, but were also notable for a buzz of interest and sometimes controversy. Two anecdotes from those years illustrate his influence and ingenuity. At that time gastrointestinal examinations were largely dependent on barium meals and enemas, for which there was a waiting list of many months except for 'emergency' appointments, which some clinicians exploited. Philip believed that if such a test was required it should be available immediately, and therefore cancelled all bookings and insisted on being the radiological arbiter on the need for these examinations, for which there would be minimal waiting time. Professor Jannie Louw, the legendary head of surgery, was incensed when he requested an emergency test and was told by his registrar that henceforth Professor Palmer would decide whether and when it would be done. The registrar was sent to demand Professor Palmer's presence, to which Philip replied that he would welcome Professor Louw in his office at any time! Barium examination bookings and procedures ran smoothly thereafter. At another meeting Philip diagnosed silicosis on a chest X-ray and was ridiculed by the clinicians, as the patient was a woman and had not been on the mines. An autopsy shortly afterwards confirmed the diagnosis of silicosis. The confirmatory diagnosis alone was insufficient for Philip, who went to Transkei and through some outstanding fieldwork demonstrated what is now known as 'hut lung?.

Philip and his wife, Miep, then moved to Philadelphia, USA. After a brief stay there, in 1970 Philip was appointed as the first professor of diagnostic radiology at the then-new UC Davis School of Medicine, California, where he remained. Often in collaboration with the World Health Organization, he continued to contribute massively, especially to radiology in developing countries and to investigation of tropical diseases. Philip was one of the most influential radiologists of his time, received many international awards, and was an inspiring teacher and leader. Among other interests, he and Miep were avid collectors of African art.

Philip's first wife, Pauline, predeceased him and he is survived by their daughter Alison, their son Robin, 3 grandchildren and two great-grandchildren, as well as his wife Miep.

J P van Niekerk, R E Kottler 